\title{
Influence of Labor on Neonatal Neutrophil Apoptosis, and Inflammatory Activity
}

\author{
BARRY WEINBERGER, ANNA M. VETRANO, KIRIN SYED, SOWMYA MURTHY, NAZEEH HANNA, \\ JEFFREY D. LASKIN, AND DEBRA L. LASKIN
}

\begin{abstract}
Departments of Pediatrics/Neonatology [B.W., A.M.V., KS, S.M., NH], Division of Neonatology and Environmental and Occupational Medicine [J.D.L.], UMDNJ-Robert Wood Johnson Medical School, New Brunswick, New Jersey 08903; Pharmacology and Toxicology [D.L.L.], Rutgers University, Piscataway, New Jersey 08854
\end{abstract}

\begin{abstract}
Neutrophil apoptosis is impaired in neonates, and this contributes to prolonged inflammation and tissue injury in infants after infection or trauma. In the present studies, we investigated whether labor generates mediators that further suppress apoptosis. We found that neutrophil apoptosis was reduced in neonates exposed to labor, when compared with infants delivered by cesarean section before labor. This was not due to alterations in caspase- 3 or inhibitor of apoptosis protein-2 (IAP-2). In contrast, labor primed neutrophils to express tumor necrosis factor $\alpha$ (TNF- $\alpha$ ), suggesting that proinflammatory mediators contribute to reduced apoptosis after labor. Eicosanoids generated via cyclooxygenase-2 (Cox-2) and lipoxygenase (Lox) also regulate neutrophil apoptosis. 15-Lox, which generates proapoptotic lipoxins, but not Cox-2, was greater in neutrophils before labor, relative to cells exposed to labor. Anti-inflammatory eicosanoids exert their effects in part via peroxisome proliferatoractivated receptor $\gamma$ (PPAR- $\gamma$ ). Expression of gelatinase-associated lipocalin and catalase, two markers of PPAR- $\gamma$ activity, were increased in neonatal neutrophils before labor, relative to cells exposed to labor. These findings suggest that the anti-inflammatory environment is maintained before labor, in part, by eicosanoids. Although increased neutrophil longevity after labor is important for host defense in the immediate newborn period, it may contribute to inflammatory or oxidative injury in susceptible infants. (Pediatr Res 61: 572-577, 2007)
\end{abstract}

Teutrophil apoptosis followed by macrophage clearance 1 is a key step in the resolution of the inflammatory response, and delays in these processes are associated with tissue injury. This has been observed in patients with acute respiratory distress syndrome, as well as oxygen-induced lung injury, pathogenic states associated with markedly reduced neutrophil apoptosis (1). Neutrophil apoptosis is also impaired in neonates when compared with adults, which is consistent with increased incidence of severe inflammatory diseases in newborns (2). We have previously demonstrated that expression of proapoptotic proteins, including members of the Bcl-2 family, as well as FasR and caspase-3, is reduced in neonatal when compared with adult neutrophils, suggesting that spe-

Received July 20, 2006; accepted December 13, 2006.

Correspondence: Barry Weinberger, M.D., Division of Neonatology, Department of Pediatrics, UMDNJ-Robert Wood Johnson Medical School, Robert Wood Johnson Place, New Brunswick, NJ 08903; e-mail: weinbebi@umdnj.edu

Supported by National Institutes of Health grants HD042036, ES005022, GM034310, ES004738, HL067708, and CA100994.

DOI: $10.1203 /$ pdr.0b013e318045be38 cific developmental defects contribute to impaired apoptosis in neonates (2).

Previous studies have suggested that the type of delivery can also influence neutrophil longevity and function. Thus, Molloy et al. (3) reported that spontaneous apoptosis is delayed in cord blood neutrophils from neonates exposed to labor relative to those delivered by cesarean section before labor. Although the mechanisms mediating the inhibitory effects of labor on neutrophil apoptosis are unknown, inflammatory mediators and hypoxic conditions associated with parturition are likely to contribute to this response. Levels of interleukin-8 (IL-8) and TNF- $\alpha$ are known to increase in the maternal circulation during labor, and these inflammatory mediators have been reported to activate neutrophils and suppress apoptosis $(4,5)$. Increases in maternal blood levels of the complement component C3b, CD11b/CD18 adhesion molecules, and IL- 8 receptors are also observed during labor, and these may contribute to decreased neutrophil apoptosis (6). Hypoxia, which can occur transiently during labor, also suppresses neutrophil apoptosis (7-9). It has been suggested that the antiapoptotic effects of inflammatory mediators and of hypoxia are due, in part, to up-regulation of proteins such as IAP-2, which block the activity of proapoptotic caspases (10).

Neutrophil apoptosis is also regulated by eicosanoids generated from arachidonic acid via Cox-2 and Lox. Whereas Cox-2 activation results in the generation of both pro- and antiapoptotic prostaglandins (PGs), metabolism of arachidonic acid via 5-Lox, 12-Lox, and 15-Lox leads to the formation of anti-inflammatory lipoxins, including lipoxin A4, which promote neutrophil apoptosis. Lipoxin A4 also inhibits neutrophil chemotaxis and cytokine production and antagonizes the proinflammatory effects of TNF- $\alpha$ (11). Anti-inflammatory eicosanoids have been reported to exert biologic effects, in part, by activating PPAR- $\gamma$ (12). This nuclear transcription factor blocks expression of inflammatory genes and upregulates antioxidants (13). These findings suggest that eico- 
sanoid signaling via PPAR- $\gamma$ plays a central role in regulating neutrophil clearance. In the present studies, we investigated alterations in neonatal neutrophil signaling pathways that may underlie increased inflammatory activity and reduced apoptosis in these cells after exposure to labor.

\section{METHODS}

Reagents. Dulbecco's modified Eagle's medium (DMEM), phosphate buffered-saline (PBS), dextran, $N$-formyl-methionyl-leucylphenylalanine (FMLP), phorbol 12-myristate 13-acetate (PMA), Hanks' balanced salt solution (HBSS), and RNase A were purchased from Sigma Chemical Co. (St. Louis, MO), and bacterial lipopolysaccharide (Escherichia coli J5 0111:B4) from Calbiochem (San Diego, CA). Ficoll-Paque was from Amersham Biosciences (Piscataway, NJ). Fluorescein-conjugated Annexin V and caspase-3 colorimetric detection kit were from R \&D Systems (Minneapolis, $\mathrm{MN}$ ), and propidium iodide from Calbiochem. 5- (and-6)-Chloromethyl-2', $7^{\prime}$ dichlorodihydrofluorescein diacetate, acetyl ester (DCF-DA) was purchased from Invitrogen (San Diego, CA). Nucleotides and reagents for real-time polymerase chain reaction (PCR) were obtained from Promega (Madison, WI) and RNA purification kits from Quiagen (Chatsworth, CA).

Subjects and neutrophil isolation. All studies were approved by the Institutional Review Board of UMDNJ-Robert Wood Johnson Medical School, and informed consent obtained from donors. Samples were obtained from the umbilical cords of healthy term infants ( $\geq 37$ wk of gestation) between May 2005 and March 2006. Infants were included in the labor group if labor was initiated at any time before cesarean or vaginal delivery. Infants in the no labor group were delivered by elective cesarean section before initiation of labor. Subjects were excluded with clinical evidence of chorioamnionitis or other perinatal bacterial or viral infections, e.g. maternal fever, uterine tenderness, or foul-smelling amniotic fluid. Deliveries were performed under standard epidural anesthesia. Peripheral venous blood drawn from antecubital veins of healthy adult volunteers was used for comparison. Neutrophils were isolated by dextran sedimentation, followed by Ficoll gradient centrifugation and hypotonic lysis of erythrocytes.

Measurement of apoptosis by Annexin V and propidium iodide staining. Neutrophils were washed, resuspended in DMEM containing 10\% fetal bovine serum, and then incubated in a shaking water bath for $24 \mathrm{~h}$. For Annexin V binding, neutrophils were centrifuged and resuspended $\left(2 \times 10^{6}\right.$ cells $/ \mathrm{mL})$ in buffer (10 mM $N$-2-hydroxyethylpiperazine- $N^{1}$-2-ethanesulfonic acid, $\mathrm{pH} 7.4,140 \mathrm{mM} \mathrm{NaCl}$, and $2.5 \mathrm{mM} \mathrm{CaCl}_{2}$ ). The cells were then incubated (15 min, room temperature) with Annexin V (1:20) and propidium iodide (1:10) and analyzed by flow cytometry on a Beckman-Coulter Cytomics FC 500 (Miami, FL). Viable apoptotic and necrotic neutrophil populations were gated electronically and data analyzed using quadrant statistics based on relative Annexin $\mathrm{V}$ and propidium iodide fluorescence. For analysis of hypodiploid DNA content, a marker of apoptosis, neutrophils were washed, resuspended in PBS $\left(1-1.5 \times 10^{6}\right.$ cells $\left./ 400 \mu \mathrm{L}\right)$, and then fixed with $3 \mathrm{~mL}$ of $70 \%$ ethanol. After $30 \mathrm{~min}$, the cells were washed and resuspended in $500 \mu \mathrm{L}$ of PBS containing $50 \mu \mathrm{L}$ of RNAse and $5 \mu \mathrm{L}$ of propidium iodide $(1 \mathrm{mg} / \mathrm{mL})$. Cells were analyzed by flow cytometry $30 \mathrm{~min}$ later. Apoptotic cells were identified by their hypodiploid DNA content as determined by histogram analysis of propidium iodide binding.

Caspase-3 activity. PMN $\left(4 \times 10^{6}\right.$ cells/mL DMEM) were lysed and centrifuged $(10,000 \times g, 1 \mathrm{~min})$. Fifty microliters of supernatants were added to each well of a 96-well plate and diluted 1:2 with buffer containing dithiothreitol (10 $\mu \mathrm{L} / \mathrm{mL})$. Caspase-3 colorimetric substrate $(5 \mu \mathrm{L}$ DEVDpNA) was added to each reaction, and the plate was incubated at $37^{\circ} \mathrm{C}$ for $1 \mathrm{~h}$ and then analyzed on a microplate reader at $405 \mathrm{~nm}$.

Analysis of mRNA expression. Neutrophils were cultured in DMEM containing 10\% FBS for $4 \mathrm{~h}$ in the absence or presence of lipopolysaccharide (LPS) $(100 \mathrm{ng} / \mathrm{mL})$. Cell suspensions were then centrifuged, and RNA isolated. For analysis of TNF- $\alpha$ and IAP-2 gene expression, reversetranscription PCR was used. For these experiments, RNA was isolated using TriZol (Invitrogen, Carlsbad, CA), and $\beta$-actin was used as standard. cDNA was prepared using the Superscript III RT kit (Invitrogen) for all experiments. The conditions for PCR amplification were denaturation for $30 \mathrm{~s}$ at $94^{\circ} \mathrm{C}$, annealing at $55^{\circ} \mathrm{C}$ for $30 \mathrm{~s}$, and elongation for $30 \mathrm{~s}$ at $72^{\circ} \mathrm{C}$, using 25 cycles. The PCR products were analyzed on a $2 \%$ agarose gel containing ethidium bromide and expression quantified by densitometry. Expression of Cox-2, 15-Lox, neutrophil gelatinase-associated lipocalin (N-Gal), catalase, and superoxide dismutase (SOD) genes was measured using real-time PCR. For these experiments, RNA was isolated using RNEasy (Quiagen). Real-time PCR was performed using the SYBR Green PCR Master Mix (Applied
Biosystems) according to the manufacturer's protocol and amplified on the ABI Prism 7900 sequence detection system, using glyceraldehyde-3-phosphate dehydrogenase (GAPDH) as standard. Full-length coding sequences for genes to be analyzed were obtained from GenBank (National Center for Biotechnology Information). PCR primers were designed using Primer Express (Applied Biosystems). The primers used were $\beta$-actin, aaggattcctatgtgggc and catctcttgctcgaagtc; TNF- $\alpha$, agcccatgttgtagcaaacc and tttgggaaggttggatgttc; IAP-2, acttgaacagctgctatccacatc and gttgctagg attttctctgaactgtc; GAPDH, tgggctacactgagcaccag and gggtgtc getgttgaagtca; Cox-2, gectgatgattgeccgact and gctggccetcgcttatgatct; $\mathrm{N}-\mathrm{Gal}$, accctcctgttggttccagc and ccetggaccctaaggaatgc; catalase, cggagattcaacactgccaa and gaatgccegcacctgagtaa; 15-Lox, agctggacatgccetacgag and cactgtttccaccacgctg; SOD, gtcgtagtctcetgcagcgtc and ctggttccgaggactgcaa.

Measurement of hydrogen peroxide production. Neutrophils, suspended in HBSS $\left(2 \times 10^{6} \mathrm{cells} / \mathrm{mL}\right)$, were incubated for $20 \mathrm{~min}$ with or without DCF-DA $\left(5 \mathrm{mM}, 37^{\circ} \mathrm{C}\right.$ shaking water bath). Cells were then treated with PMA $\left(500 \mathrm{nM}, 37^{\circ} \mathrm{C}\right.$ shaking water bath) or medium control. After $20 \mathrm{~min}$, HBSS was added and fluorescence quantified by flow cytometry.

Data analysis. Statistical analysis was performed using Statistica 6.0 (StatSoft, Inc., Tulsa, OK). Data are presented as mean \pm standard error (SE). Normal distribution was confirmed using the Kolmogorov-Smirnov test. The effects of treatments by group were compared by $2 \times 3$ ANOVA. Post hoc analysis was performed using the least significant difference test. A $p$ value $<0.05$ was considered statistically significant.

\section{RESULTS}

Initially we analyzed the effects of exposure to labor on apoptosis in neonatal neutrophils. We found that apoptosis, as measured by Annexin V binding and hypodiploid DNA content, was significantly reduced in neutrophils from neonates exposed to labor when compared with cells collected from infants delivered by cesarean section before labor (Fig. 1). In both neonatal cell populations, apoptosis was significantly reduced when compared with adult cells, which is consistent with previous reports $(1,2,14)$. In further studies, we analyzed potential mechanisms underlying the inhibitory effects of labor on neonatal neutrophil apoptosis. The activity of caspase-3, an important effector enzyme in the pathway of apoptosis, was detectable in neonatal neutrophils from both the labor and no labor groups. Although caspase activity was significantly reduced in neutrophils from neonates when compared with adults, no differences were observed between cells exposed and not exposed to labor (Fig. 2). Similarly, IAP-2 was expressed in neutrophils from both the labor and no labor groups, but no differences were observed between the cell types. IAP-2 expression was, however, markedly reduced in cells from neonates, relative to adults.

To investigate the possibility that labor primes neutrophils to generate inflammatory mediators that modulate apoptosis, we measured expression of TNF- $\alpha$. Untreated neutrophils from neonates in both the labor and no labor groups expressed low levels of TNF- $\alpha$ (Fig. 3). Treatment of the cells with bacterially derived LPS significantly increased TNF- $\alpha$ expression. Greater TNF- $\alpha$ expression was noted in neutrophils from neonates exposed to labor when compared with cells not exposed to labor. Adult neutrophils were also found to express TNF- $\alpha$ in response to LPS. This activity was significantly greater than in cells from neonates.

We next analyzed the effects of labor on expression of the eicosanoid-generating enzymes Cox-2 and 15-Lox. Neonatal neutrophils from both the labor and no labor groups expressed Cox-2 and 15-Lox mRNA (Fig. 4). Whereas no differences were noted in Cox-2 expression between the neonatal cell 

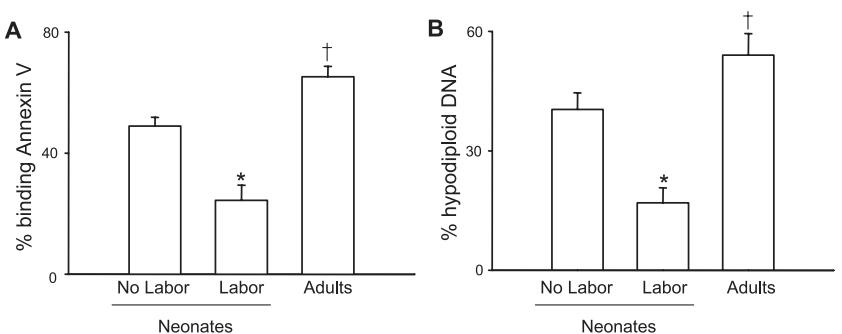

Figure 1. Effects of labor on apoptosis in neonatal neutrophil. Cord blood neutrophils collected after labor or after cesarean section before labor (no labor) were cultured for $24 \mathrm{~h}$ before analysis. Apoptosis was quantified as the percentage of cells binding Annexin V $(A)$ or by the percentage of cells with hypodiploid DNA content as determined by propidium iodide binding $(B)$. Data were analyzed using Coulter quadrant and two-dimensional histogram statistics based on relative fluorescence. Samples from healthy adults were analyzed for comparison. Each bar represents the mean \pm SE of 12 samples. $*$ Significantly different $(p<0.05)$ from no labor; $\uparrow$ significantly different $(p<$ $0.05)$ from neonates.

types, a significant decrease in expression of 15-Lox was noted in neutrophils exposed to labor, when compared with cells not exposed to labor. We also found that expression of Cox-2 was significantly reduced in both neonatal neutrophil populations relative to adults. In contrast, expression of 15 Lox was increased in neonatal neutrophils not exposed to labor, when compared with adult cells. N-Gal is a proapoptotic protein thought to be induced by anti-inflammatory eicosanoids $(15,16)$. N-Gal mRNA expression was found to be decreased in neutrophils from neonates exposed to labor when compared with neutrophils not exposed to labor. N-Gal expression in neutrophils collected before labor was also increased relative to adult cells (Fig. 4).

In further studies, we measured production of reactive oxygen intermediates (ROIs), which have been reported to possess proapoptotic activity (17). Both neonatal and adult neutrophils produced ROIs (Fig. 5). Moreover, both cell populations were highly responsive to stimulation with PMA, generating two- to threefold greater quantities of ROI. Whereas basal oxidative metabolism in neutrophils from neonates exposed to labor was significantly greater than cells from adults, their responsiveness to PMA was similar (Fig. 5). Neonatal neutrophils from both the labor and no labor groups were found to constitutively express the antioxidant enzymes catalase and SOD, which detoxify ROIs (Fig. 4). However, markedly reduced levels of catalase were detected in neutrophils exposed to labor. Expression of catalase was significantly increased in neonatal cells, when compared with adult cells. Although SOD was also increased in neonatal neutrophils when compared with adult cells, there was no difference between the labor and no labor groups.

\section{DISCUSSION}

Labor is associated with increased production of proinflammatory mediators such as interferon- $\gamma$ and TNF- $\alpha$, and decreased release of IL-10, a potent anti-inflammatory cytokine, and these changes are thought to play a role in the onset of parturition (18). Proinflammatory mediators have also been
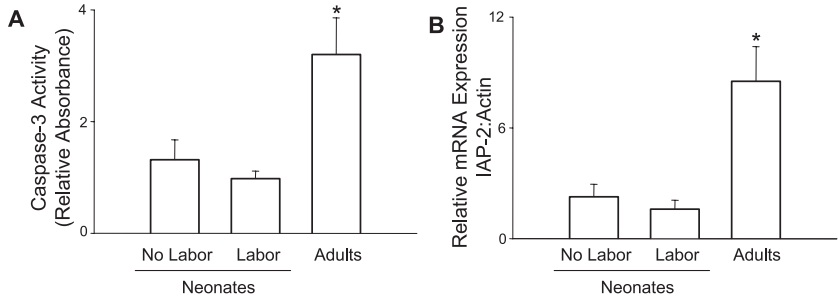

Figure 2. Effects of labor on caspase 3 activity and IAP-2 expression in neutrophils. Cord blood neutrophils were collected after labor or after cesarean section before labor (no labor). (A) Freshly isolated cells were analyzed for caspase-3 activity as described in the Methods section. (B) Cells were analyzed for expression of IAP-2 using reverse transcription PCR. Data were normalized to $\beta$-actin expression. Samples from healthy adults were analyzed for comparison. Each bar represents the mean \pm SE of six samples. *Significantly different $(p<0.05)$ from neonates.

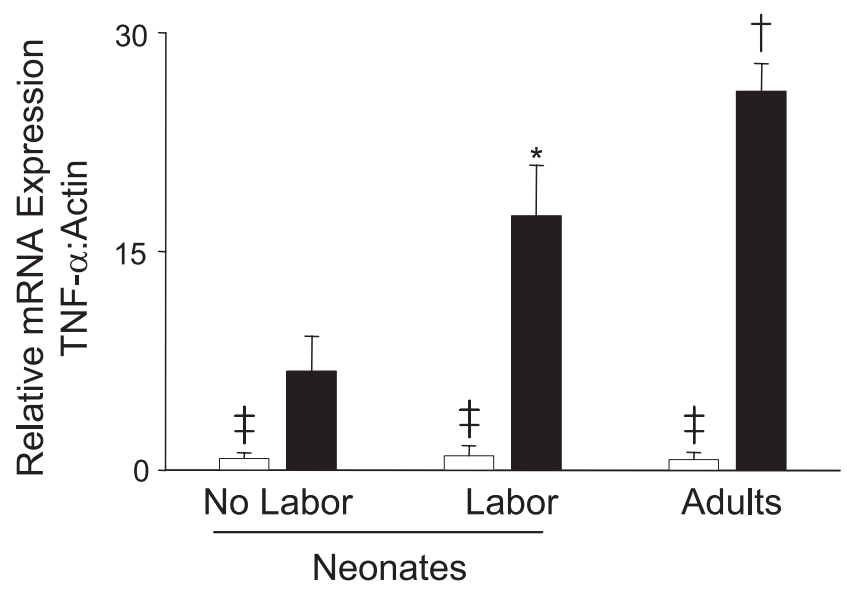

Figure 3. Effect of labor on expression of TNF- $\alpha$. Cord blood neutrophils collected after labor or after cesarean section before labor (no labor) were incubated with (filled columns) or without (open columns) LPS (100 ng/mL) for $4 \mathrm{~h}$ before analysis by reverse transcription PCR. Data were normalized to $\beta$-actin expression. Samples from healthy adults were analyzed for comparison. Each bar represents the mean $\pm \mathrm{SE}$ of six samples. *Significantly different $(p<0.05)$ from no labor; $\dagger$ significantly different $(p<0.05)$ from neonates; $\ddagger$ significantly different from LPS.
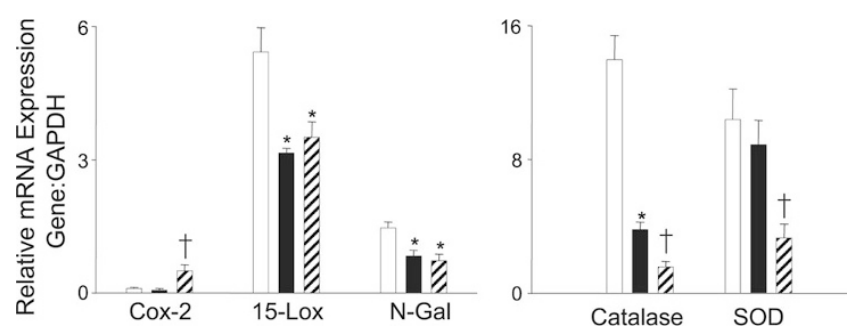

Figure 4. Effects of labor on genes regulating eicosanoid and antioxidant production. Cord blood neutrophils collected after labor (filled columns) or after cesarean section prior to labor (open columns) were analyzed by real-time PCR. Data were normalized to GAPDH expression. Samples from healthy adults (hatched columns) were analyzed for comparison. Each bar represents the mean $+\mathrm{SE}$ of eight to 15 samples. * Significantly different $(p<0.05)$ from no labor; $\uparrow$ significantly different $(p<0.05)$ from neonates.

shown to promote neutrophil activation and longevity (4). The present studies demonstrate that neonatal neutrophils exposed to the proinflammatory environment of labor exhibit significantly reduced apoptosis, when compared with neutrophils 

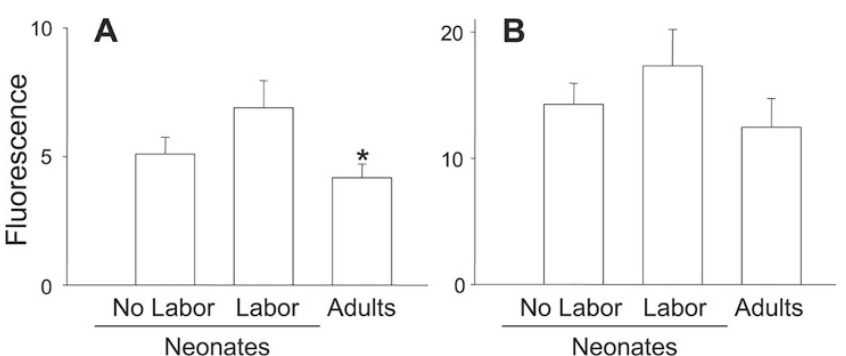

Figure 5. Effect of labor on hydrogen peroxide production. Cord blood neutrophils collected after labor or after cesarean section before labor (no labor) were preincubated with DCF-DA $\left(5 \mathrm{mM}, 37^{\circ} \mathrm{C}\right)$ for $20 \mathrm{~min}$ and then with PMA $(500 \mathrm{nM})(B)$ or medium control $(A)$. Hydrogen peroxide production was quantified as DCF fluorescence by flow cytometry 20 min later. Samples from healthy adults were analyzed for comparison. Each bar is the mean \pm SE of six to eight samples. *Significantly different $(p<0.05)$ from neonates.

collected from neonates delivered by cesarean section and not exposed to labor. By increasing the longevity of circulating neutrophils in neonates, the process of labor may be beneficial in healthy infants, helping to prime the naïve immune system to respond to pathogens. In contrast, decreased clearance of neutrophils after labor in compromised or premature infants may contribute to complications associated with chronic inflammation, such as bronchopulmonary dysplasia and necrotizing enterocolitis.

Neutrophil apoptosis involves spontaneous mitochondrial depolarization, leading to the release of cytochrome $c$ and activation of downstream proteases, including caspase- 3 and caspase-7 (19). The rate of apoptosis is related to the activity of these effector pathways, which induce cell and nuclear membrane permeability (13). Consistent with previous findings $(2,14)$, we found that apoptosis is impaired in neonatal neutrophils relative to adult cells and that this is associated with reduced caspase- 3 activity in neonatal cells. Interestingly, labor had no effect on caspase-3 activity or on expression of IAP-2, an intracellular protein induced by inflammatory stimuli and hypoxia that inhibits caspase activity (20). These findings suggest that the antiapoptotic effects of labor are mediated by alternative pathways. One possibility is that other homologues of IAP contribute to inflammation-induced suppression of neutrophil apoptosis. For example, increased XIAP, and decreased XIAP inhibitory protein, have been reported in neutrophils from patients with systemic inflammatory reactive syndrome (19). These alterations may contribute to decreased caspase-mediated apoptosis after the stimulus of labor.

Inflammatory mediators derived from maternal phagocytic leukocytes are important in triggering both uterine activity and placental separation. These mediators readily pass through the placental barrier, gaining access to the fetal circulation (21). This may contribute to increased expression of the complement component C3b, CD11b/CD18 adhesion molecules, and IL-8 receptors in neonatal neutrophils after exposure to labor (22). The present studies confirm that labor primes neonatal neutrophils to respond to inflammatory stimuli. Thus, expres- sion of TNF- $\alpha$ in response to LPS is significantly increased in neutrophils from neonates after labor, when compared with cells collected before labor. TNF- $\alpha$ activates neutrophils and monocytes and is thought to be important in host defense and the suppression of apoptosis during neutrophilic inflammation in the newborn period (23). However, excessive production of TNF- $\alpha$ in response to pathologic stimuli after labor may also contribute to the development of periventricular leukomalacia (24).

Lipoxygenase catalyzes the synthesis of lipoxins, which promote apoptosis (11). Lipoxin A4 and lipoxin B4 also exert anti-inflammatory activity by inhibiting neutrophil chemotaxis and CD11/CD18 expression, and by abrogating calcium mobilization, respiratory burst activity, release of IL- $1 \beta$ and IL-8, and activation of the transcription factors nuclear factor- $\kappa \mathrm{B}$ $(\mathrm{NF}-\kappa \mathrm{B})$ and AP-1 $(11,25,26)$. Previous studies have demonstrated that deficiency in production of lipoxin A4 is associated with defects in neutrophil apoptosis and with chronic inflammation (27). In contrast to Loxs, Cox-2 catalyzes the production of proinflammatory eicosanoids during the early stages of inflammation, which block neutrophil apoptosis (28). We found that expression of 15-Lox is significantly increased in neonatal neutrophils isolated before labor, when compared with cells collected after exposure to labor. In contrast, labor had no effect on expression of Cox-2. These findings suggest that anti-inflammatory lipoxins may be increased relative to proinflammatory PGs before birth. This is consistent with the idea that an anti-inflammatory environment in utero is required for maintaining pregnancy (22). In this regard, defects in production of the anti-inflammatory cytokine IL-10 are associated with preterm labor (29). Moreover, increases in PGs in the circulation are thought to be important in triggering uterine contractions, and Cox-2 inhibitors are effective tocolytic agents (30).

PPAR- $\gamma$ is a key transcription factor mediating the proapoptotic and anti-inflammatory activity of eicosanoids (31). PPAR- $\gamma$ agonists inhibit expression of inflammatory cytokines and oxidants and up-regulate expression of proteins with anti-inflammatory activity, including N-Gal (16). N-Gal promotes neutrophil differentiation and clearance and has been used as a marker of PPAR- $\gamma$ activity (15). The present studies show that $\mathrm{N}-\mathrm{Gal}$ is differentially expressed in neonatal neutrophils before and after exposure to labor. Thus, whereas relatively high levels of $\mathrm{N}-\mathrm{Gal}$ were detected in neutrophils before labor, after labor N-Gal levels declined significantly and were similar to expression levels in adult neutrophils. These findings are in accord with the concept that antiinflammatory PPAR- $\gamma$ activity is high before parturition (32). PPAR- $\gamma$ may also contribute to maintenance of the antiinflammatory milieu in utero. This is important for suppressing maternal immune responses that can cause preterm labor and rejection of the fetal allograft.

The relatively short life span of neutrophils is thought to be related to their oxidant/antioxidant balance. We found that basal oxidative metabolism was increased in neonatal neutrophils exposed to labor, when compared with adult cells. However, labor did not significantly alter basal oxidative 
metabolism, or the production of ROIs in response to PMA in neonatal neutrophils. Our observation that labor had no effect on oxidative metabolism in neonatal neutrophils was surprising. Labor is associated with the generation of inflammatory cytokines, including IL-6 and IL-8, which are known to stimulate the production of ROIs in neutrophils (33). These findings are consistent with previous reports that the oxidative response to inflammatory mediators is impaired in term neonatal neutrophils $(34,35)$. Decreased responsiveness to inflammatory stimuli may be related to defects in the activation of signaling via the nuclear transcription factors STAT-1 and $\mathrm{NF}-\kappa \mathrm{B}$ in neonatal cells (36).

Antioxidants such as catalase and SOD play important roles in detoxifying oxidants $(37,38)$. We found that catalase expression was markedly increased in neonatal neutrophils isolated before labor, when compared with cells from neonates exposed to labor or from adults. Catalase has been reported to be induced by PPAR- $\gamma$, which, as indicated above, is also activated in neonates before labor (39). Elevated levels of catalase during gestation may help to protect placental tissues from oxidants generated by neutrophils and mononuclear cells in the fetal and maternal circulations. In contrast to catalase, SOD expression was not affected by labor and was significantly increased in neonatal neutrophils, when compared with adult cells. During and after labor, SOD may be important in protecting the newborn from the effects of ambient oxygen and exposure to pathogenic stimuli. Consistent with this notion are reports that exogenous SOD, but not catalase, protects against inflammatory lung injury in neonates (40).

The present studies demonstrate that the process of labor is associated with reduced neutrophil apoptosis. This was correlated with alterations in eicosanoid signaling and TNF- $\alpha$ expression. Increased neutrophil longevity and activity may protect the newborn against pathogens and potentiate the inflammatory response to infection or injury. However, these effects can potentially be maladaptive in infants exposed to preexisting inflammatory conditions, including chorioamnionitis and prematurity. It is speculated that reduced neutrophil clearance by apoptosis and impaired production of antiinflammatory eicosanoids and antioxidant enzymes may increase the risk of cytotoxicity and "oxygen radical diseases" in preterm or compromised neonates exposed to labor. An understanding of the factors that regulate neutrophil apoptosis is essential for the development of efficacious therapies and strategies for limiting neonatal inflammatory diseases.

\section{REFERENCES}

1. Oei J, Lui K, Wang H, Henry R 2003 Decreased neutrophil apoptosis in tracheal fluids of preterm infants at risk of chronic lung disease. Arch Dis Child Fetal Neonatal Ed 88:F245-F249

2. Hanna N, Vasquez P, Pham P, Heck DE, Laskin JD, Laskin DL, Weinberger B 2005 Mechanisms underlying reduced apoptosis in neonatal neutrophils. Pediatr Res 57:56-62

3. Molloy EJ, O'Neill AJ, Grantham JJ, Sheridan-Pereira M, Fitzpatrick JM, Webb DW, Watson RW 2004 Labor promotes neonatal neutrophil survival and lipopolysaccharide responsiveness. Pediatr Res 56:99-103

4. Akgul C, Moulding DA, Edwards SW 2001 Molecular control of neutrophil apoptosis. FEBS Lett 487:318-322

5. Walmsley SR, Cowburn AS, Sobolewski A, Murray J, Farahi N, Sabroe I, Chilvers ER 2004 Characterization of the survival effect of tumour necrosis factor-alpha in human neutrophils. Biochem Soc Trans 32:456-460
6. Gessler P, Dahinden C 2003 Increased respiratory burst and increased expression of complement receptor-3 (CD11b/CD18) and of IL-8 receptor-A in neutrophil granulocytes from newborns after vaginal delivery. Biol Neonate 83:107-112

7. Walmsley SR, Print C, Farahi N, Peyssonnaux C, Johnson RS, Cramer T, Sobolewski A, Condliffe AM, Cowburn AS, Johnson N, Chilvers ER 2005 Hypoxia-induced neutrophil survival is mediated by HIF-1alpha-dependent NF-kappaB activity. J Exp Med 201:105-115

8. Molloy EJ, O'Neill AJ, Doyle BT, Grantham JJ, Taylor CT, Sheridan-Pereira M, Fitzpatrick JM, Webb DW, Watson RW 2006 Effects of heat shock and hypoxia on neonatal neutrophil lipopolysaccharide responses: altered apoptosis, Toll-like receptor-4 and CD11b expression compared with adults. Biol Neonate 90:34-39

9. Hanna N, Graboski S, Laskin DL, Weinberger B 2004 Effects of ibuprofen and hypoxia on neutrophil apoptosis in neonates. Biol Neonate 86:235-239

10. O'Neill AJ, Doyle BT, Molloy E, Watson C, Phelan D, Greenan MC, Fitzpatrick JM, Watson RW 2004 Gene expression profile of inflammatory neutrophils: alterations in the inhibitors of apoptosis proteins during spontaneous and delayed apoptosis Shock 21:512-518

11. McMahon B, Godson C 2004 Lipoxins: endogenous regulators of inflammation. Am J Physiol Renal Physiol 286:F189-F201

12. Scher JU, Pillinger MH 2005 15d-PGJ2: the anti-inflammatory prostaglandin? Clin Immunol 114:100-109

13. Garcia-Bueno B, Madrigal JL, Lizasoain I, Moro MA, Lorenzo P, Leza JC 2005 Peroxisome proliferator-activated receptor gamma activation decreases neuroinflammation in brain after stress in rats. Biol Psychiatry 57:885-894

14. Allgaier B, Shi M, Luo D, Koenig JM 1998 Spontaneous and Fas-mediated apoptosis are diminished in umbilical cord blood neutrophils compared with adult neutrophils. J Leukoc Biol 64:331-336

15. Logdberg L, Wester L 2000 Immunocalins: a lipocalin subfamily that modulates immune and inflammatory responses. Biochim Biophys Acta 1482:284-297

16. Youssef J, Badr M 2004 Role of peroxisome proliferator-activated receptors in inflammation control. J Biomed Biotechnol 2004:156-166

17. Fadeel B, Ahlin A, Henter JI, Orrenius S, Hampton MB 1998 Involvement of caspases in neutrophil apoptosis: regulation by reactive oxygen species. Blood 92:4808-4818

18. Hanna N, Bonifacio L, Weinberger B, Reddy P, Murphy S, Romero R, Sharma S 2006 Evidence for interleukin-10-mediated inhibition of cyclo-oxygenase-2 expression and prostaglandin production in preterm human placenta. Am J Reprod Immunol 55:19-27

19. O’Neill A, Greenan MC, Doyle B, Fitzpatrick JM, Watson RW 2004 Gene profiling of in vitro and in vivo models of delayed neutrophil apoptosis: a common pathway? Biochem Soc Trans 32:470-473

20. Wang CY, Mayo MW, Korneluk RG, Goeddel DV, Baldwin AS Jr. 1998 NFkappaB antiapoptosis: induction of TRAF1 and TRAF2 and c-IAP1 and c-IAP2 to suppress caspase- 8 activation. Science 281:1680-1683.

21. Leitich H 2005 Controversies in diagnosis of preterm labour. Br J Obstet Gynaecol 112:61-63

22. Park JS, Park CW, Lockwood CJ, Norwitz ER 2005 Role of cytokines in preterm labor and birth. Minerva Ginecol 57:349-366

23. Speer CP 1999 Inflammatory mechanisms in neonatal chronic lung disease. Eur J Pediatr 158:S18-S22

24. Rezaie P, Dean A 2002 Periventricular leukomalacia, inflammation and white matter lesions within the developing nervous system. Neuropathology 22:106-132

25. Lee TH, Horton CE, Kyan-Aung U, Haskard D, Crea AE, Spur BW 1989 Lipoxin A4 and lipoxin B4 inhibit chemotactic responses of human neutrophils stimulated by leukotriene B4 and N-formyl-L-methionyl-L-leucyl-L-phenylalanine. Clin Sci (Lond) 77:195-203

26. Filep JG, Zouki C, Petasis NA, Hachicha M, Serhan CN 2002 Lipoxin A4 and aspirin-triggered 15-epi-lipoxin A4 modulate adhesion molecule expression on human leukocytes in whole blood and inhibit neutrophil-endothelial cell adhesion. Adv Exp Med Biol 507:223-228

27. Kantarci A, Van Dyke TE 2003 Lipoxins in chronic inflammation. Crit Rev Oral Biol Med 14:4-12

28. Ottonello L, Gonella R, Dapino P, Sacchetti C, Dallegri F 1998 Prostaglandin E2 inhibits apoptosis in human neutrophilic polymorphonuclear leukocytes: role of intracellular cyclic AMP levels. Exp Hematol 26:895-902

29. Hanna N, Hanna I, Hleb M, Wagner E, Dougherty J, Balkundi D, Padbury J, Sharma S 2000 Gestational age-dependent expression of IL-10 and its receptor in human placental tissues and isolated cytotrophoblasts. J Immunol 164:5721-5728

30. Vermillion ST, Landen CN 2001 Prostaglandin inhibitors as tocolytic agents. Semin Perinatol 25:256-262

31. Chinetti G, Fruchart JC, Staels B 2000 Peroxisome proliferator-activated receptors (PPARs): nuclear receptors at the crossroads between lipid metabolism and inflammation. Inflamm Res 49:497-505

32. Lappas M, Permezel M, Georgiou HM, Rice GE 2002 Regulation of proinflammatory cytokines in human gestational tissues by peroxisome proliferator-activated receptor-gamma: effect of 15-deoxy-Delta(12,14)-PGJ(2) and troglitazone. J Clin Endocrinol Metab 87:4667-4672

33. Victor VM, Rocha M, De la Fuente M 2004 Immune cells: free radicals and antioxidants in sepsis. Int Immunopharmacol 4:327-347

34. Bortolussi R, Howlett S, Rajaraman K, Halperin S 1993 Deficient priming activity of newborn cord blood-derived polymorphonuclear neutrophilic granulocytes with lipopolysaccharide and tumor necrosis factor-alpha triggered with formylmethionyl-leucyl-phenylalanine. Pediatr Res 34:243-248 
35. Komatsu H, Tsukimori K, Hata K, Satoh S, Nakano H 2001 The characterization of superoxide production of human neonatal neutrophil. Early Hum Dev 65:11-19

36. Marodi L, Goda K, Palicz A, Szabo G 2001 Cytokine receptor signalling in neonatal macrophages: defective STAT-1 phosphorylation in response to stimulation with IFN-gamma. Clin Exp Immunol 126:456-460

37. Kinnula VL, Soini Y, Kvist-Makela K, Savolainen ER, Koistinen P 2002 Antioxidant defense mechanisms in human neutrophils. Antioxid Redox Signal 4:27-34

38. Asikainen TM, White CW 2004 Pulmonary antioxidant defenses in the preterm newborn with respiratory distress and bronchopulmonary dysplasia in evolution: implications for antioxidant therapy. Antioxid Redox Signal 6:155-167

39. Girnun GD, Domann FE, Moore SA, Robbins ME 2002 Identification of a functional peroxisome proliferator-activated receptor response element in the rat catalase promoter. Mol Endocrinol 16:2793-2801

40. Davis JM, Parad RB, Michele T, Allred E, Price A, Rosenfeld W 2003 Pulmonary outcome at 1 year corrected age in premature infants treated at birth with recombinant human CuZn superoxide dismutase. Pediatrics 111:469-476 